\title{
Variation of Elastic Parameters of CdS:Ho Nanofluid- An Ultrasonic Study
}

\author{
GEORGE VARUGHESE $^{1 *}$ and K.T. USHA ${ }^{2}$ \\ ${ }^{1}$ Department of Physics, Catholicate College, Pathanamthitta, Kerala-689645, India \\ ${ }^{2}$ Department of Chemistry, St. Cyrils College, Adoor, Kerala, India \\ gvushakoppara@yahoo.co.in
}

Received 18 July 2014 / Accepted 26 July 2014

\begin{abstract}
CdS is having many optoelectronic applications including solar cell, photodiode, light emitting diode, non linear optics, heterogeneous catalysis. Holmium doped CdS nanoparticles were prepared by chemical precipitation route. The particle size was determined from the x-ray line broadening. Samples were characterized by XRD, FTIR, SEM and EDS. The size of the particles has been increased from $13.4 \mathrm{~nm}$ to $16.7 \mathrm{~nm}$ as the calcination temperature was increased. Ultrasonic velocity through doped sample was measured. Also variation of compressibility of CdS: Ho nanofluid with various grain size have been carried out and found that compressibility increases with decrease of particle size. The elastic properties of the nanofluid has been studied extensively. Certain important physical parameters such as adiabatic compressibility, specific acoustic impedance, relative association, intermolecular free length, Rao's constant, Wada's constant of holmium doped Cadmium sulphide nanofluid were evaluated and variation of these acoustic parameters with temperature and particle size were reported.
\end{abstract}

Keywords: Semiconductor, Nanomaterials, Doping, Ultrasonic velocity

\section{Introduction}

Cadmium sulfide has hexagonal wurtzite structure and the cubic zinc blende structure Cadmium sulfide is a direct band gap II-VI semiconductor $(2.42 \mathrm{eV})$. CdS has discrete energy levels, tunable band gap, size dependent optical properties and well developed synthetic protocols, good chemical stability ${ }^{1}$. CdS is having many optoelectronic applications including solar cell, photodiode, light emitting diode, non linear optics, heterogeneous catalysis ${ }^{2}$. The conductivity increases when irradiated with light leading to uses as a photo resistor. Both polymorphs are piezoelectric and the hexagonal is also pyroelectric. Electroluminescence CdS crystal can act as a solid state laser ${ }^{3}$, Molecular weight $144.46 \mathrm{~g} / \mathrm{mole}$, Density $4.82 \mathrm{~g} / \mathrm{cm}^{3}$, Crystal system Cubic Lattice type = Primitive Space group $=\mathrm{C}_{6 \ddot{v}} 4$ Cell parameters: $\mathrm{a}=5.8360 \AA, \mathrm{b}=5.8360 \AA, \mathrm{c}=5.8360 \AA . \mathrm{CdS}$ and cadmium selenide are used in manufacturing of photo resistors sensitive to visible and near infrared light ${ }^{4}$. Since CdS has $2.42 \mathrm{eV}(515 \mathrm{~nm})$ band gap, it is the most promising candidate 
among II-VI compounds for detecting visible radiation ${ }^{5,6}$. Cadmium sulfide is also used in the production of solar cells where it is used as a buffer layer in the manufacture of CIGS (Copper Indium-Gallium-Selenide) solar cells ${ }^{2}$. No study about elastic properties of CdS:Ho are reported in the literature. Hence the aim of the investigation is to study the variation of elastic parameters adiabatic compressibility, Wada's constant, Rao's constant, acoustic impedance, free length, relative association of holmium ions doped $\mathrm{CdS}$ nanofluid with temperature and particle size.

\section{Experimental}

CdS nanoparticles were prepared by the proper mixing of cadmium chloride and sodium sulphide solutions. CdS nanoparticles were grown by the chemical precipitation method at room temperature. In synthesis procedure $100 \mathrm{~mL}$ aqueous solution of the reactants was prepared. $0.1 \mathrm{M}$ of $\mathrm{CdCl}_{2}, 0.1 \mathrm{M}$ of $\mathrm{Na}_{2} \mathrm{~S}$ and $0.1 \mathrm{M}$ of $\left[\mathrm{Ho}\left(\mathrm{OH}_{2}\right)_{9}\right]^{3+}$ complexes in dilute sulfuric acid were used as the reactant materials. Freshly prepared aqueous solution of $0.1 \mathrm{M} \mathrm{Na}_{2} \mathrm{~S}$ was mixed drop by drop in the $0.1 \mathrm{M} \mathrm{CdCl}_{2}$ solution using vigorous stirring. As the reaction was started the reaction system gradually changed from transparent to light yellow and after completion of reaction this turn to dark yellow. Five drops of triethyleamine (TEA) was added to the solution to reduce the agglomeration of particles. The precipitate was then washed several times with ethanol and then with acetone and centrifuged. The precipitate collected from centrifugation was dried at $50{ }^{\circ} \mathrm{C}$ for 3 hours. After annealing sample was taken and made into fine powder form.

The XRD of the powder were studied using Rigaku DMAX diffractometer using $\mathrm{Cu}$ $\mathrm{K} \alpha$ radiation monochromatised with a graphite crystal and high temperature attachment in $\theta-2 \theta$ geometry. Data in JCPDS file can compare with observed values. The nanoparticles were characterized by FTIR, SEM and EDS.

In this investigation, ultra sound technique was used to measure velocity of the sound through the CdS:Ho nanofluid. Speed of sound was measured by using a variable path, single crystal interferometer. (Mittal Enterprises, New Delhi). Ultrasonic velocity was measured with an accuracy $\pm 0.1 \%$ and error of measurement $\pm 0.5{ }^{\circ} \mathrm{C}$ at $303 \mathrm{~K}$. The various acoustic parameters are evaluated using ultrasonic velocity, compressibility and densities ${ }^{7}$.

\section{Results and Discussion}

\section{Particle size determination}

XRD techniques are widely used for the particle size determination of nanoparticles. Width of the diffraction lines and their shape were characteristic of the crystalline size and the micro strain. If the line broadening is only due to small crystalline size, the size of the crystalline can be estimated from the Scherrer's formula ${ }^{8,9}$.

$$
\mathrm{L}=\mathrm{k} \lambda / \beta \cos \theta
$$

Where $\theta$ is the Bragg's angle, $\lambda$ is the wave length of the $\mathrm{x}$-rays, $\mathrm{L}$ is the mean dimension of the crystalline size of the powder sample, $\beta$ is the full width at half maximum of the diffraction at $2 \theta$ scale in the radius, $\mathrm{k}$ is the constant approximately equal to 0.9 . Particle size at 80 and $100{ }^{\circ} \mathrm{C}$ are tabulated in Table 1.

Table 1. Variation of particle size of CdS:Ho nanoparticle with temperature

\begin{tabular}{cccccc}
\hline Temp., ${ }^{\circ} \mathrm{C}$ & FWHM & $\beta \times, 10^{-3}$ & $2 \theta$ & $\theta$ & $\begin{array}{c}\text { Particle size } \\
(\mathrm{L}) \mathrm{Nm}\end{array}$ \\
\hline 80 & 0.8029 & 14.006 & 26.61 & 13.05 & 13.39 \\
100 & 0.6528 & 11.39 & 51.77 & 25.88 & 16.73 \\
\hline
\end{tabular}


From the data presented in Table 1 it is found that particle size of nanoparticles of CdS:Ho increases with temperature. The change in particle size causes large variation in the physical properties since $1 \mathrm{~nm}$ size change may introduce a considerable change in the number of surface atoms with lower co-ordination and broken exchange bonds.

\section{Variation of elastic parameters with grain size and temperature of CdS:Ho Nanofluid}

An ultrasonic interferometer is a simple and direct device to determine the ultrasonic velocity in liquids with high degree of accuracy. The principle used in the measurement of velocity is based on the accurate determination of the wave length in the medium. $2 \mathrm{~g}$ of CdS:Ho dissolved in $5 \mathrm{~mL}$ of ethylene glycol is taken in the cell. The wavelength of ultrasonic waves of frequency $2 \mathrm{MHz}$ is found out. If the distance is now increased or decreased and the variation exactly one half wavelength or multiple of it, anode current again becomes maximum, from the knowledge of wavelength the velocity, compressibility and relative association $^{7}$ of CdS: Ho nanofluid can be determined by the relation and presented in Table 2 . Where $\rho$ is the density of the fluid and $\mathrm{v}$ is the ultrasonic velocity of the mixture.

Table 2. Measurement of ultrasonic velocity, compressibility and relative association in $\mathrm{CdS} ;$ Ho nanofluid and in ethylene glycol at $303 \mathrm{~K}$

\begin{tabular}{|c|c|c|c|c|c|c|c|}
\hline Fluid & Readings & $\lambda / 2$ & $\begin{array}{c}\text { Mean } \\
\lambda / 2\end{array}$ & $\lambda$ & $\begin{array}{l}\text { Velocity } \\
\text { (V) } \mathrm{m} / \mathrm{s}\end{array}$ & $\begin{array}{c}\text { Compressibility } \\
\mathrm{B}=1 / \rho \mathrm{V}^{2} \\
\times(\AA)\end{array}$ & $\begin{array}{c}\text { Relative } \\
\text { Association } \\
\mathrm{R}_{\mathrm{a}=} \rho_{\mathrm{s}} / \rho_{\mathrm{o}}\left(\mathrm{V}_{\mathrm{o}} / \mathrm{V}_{\mathrm{s}}\right) \\
\end{array}$ \\
\hline $\begin{array}{c}\text { CdS:Ho } \\
\text { Nanofluid }\end{array}$ & $\begin{array}{l}11.065 \\
11.163 \\
11.260 \\
11.349 \\
11.446 \\
11.532 \\
11.630 \\
11.722 \\
11.820 \\
11.911 \\
12.001 \\
\end{array}$ & $\begin{array}{l}0.098 \\
0.097 \\
0.089 \\
0.097 \\
0.086 \\
0.098 \\
0.092 \\
0.098 \\
0.091 \\
0.090 \\
\end{array}$ & 0.0936 & 0.1872 & 374.4 & 14.8 & 5.82 \\
\hline $\begin{array}{c}\text { Ethylene } \\
\text { glycol }\end{array}$ & $\begin{array}{l}11.889 \\
11.797 \\
11.708 \\
11.615\end{array}$ & $\begin{array}{l}0.092 \\
0.089 \\
0.093\end{array}$ & 0.0913 & 0.1826 & 913.3 & 67.18 & \\
\hline
\end{tabular}

Density of CdS:Ho nanofluid, $\rho=4.82 \times 10^{3} \mathrm{~kg} / \mathrm{m}^{3}$, Frequency of ultrasound in CdS:Ho nanofluid, $f=2 \mathrm{MHz}$. and through ethylene glycol is $5 \mathrm{~Hz}$, Density of Ethylene glycol, $\rho=1.1132 \times 10^{3} \mathrm{~kg} / \mathrm{m}^{3}$, Molar mass of $\mathrm{Cd} \mathrm{S:Ho}=144.226 \mathrm{~g} / \mathrm{mole}$

Table 3. Variation of compressibility, bulk modulus, Wada's constant, ultrasonic velocity with particle size and temperature of CdS:Ho nanofluid

\begin{tabular}{cccccc}
\hline $\begin{array}{c}\text { Temperature } \\
{ }^{\circ} \mathrm{C}\end{array}$ & $\begin{array}{c}\text { Particle } \\
\text { size }(\mathrm{L}) \mathrm{nm}\end{array}$ & $\begin{array}{c}\text { Ultrasonic } \\
\text { velocity } \\
(\mathrm{m} / \mathrm{s})\end{array}$ & $\begin{array}{c}\text { Compres. } \\
\beta(\AA)\end{array}$ & $\begin{array}{c}\text { Wada's } \\
\text { constant } \\
\mathrm{W}=(\mathrm{M} / \rho)(\beta)^{-1 / 7} \\
\times 10^{-4} \mathrm{~m}^{3} / \mathrm{mole}\end{array}$ & $\begin{array}{c}\text { Bulk } \\
\text { modulus } \\
\mathrm{K}=1 / \beta \\
\left(10^{10}\right) \mathrm{N} / \mathrm{m}^{2}\end{array}$ \\
\hline 80 & 13.39 & 374.3 & 14.8 & 54.85 & 0.0675 \\
100 & 16.73 & 379.5 & 14.4 & 55.06 & 0.0694 \\
\hline
\end{tabular}


An increase in bulk modulus (Table 3) or decrease in compressibility is attributed to the fact that strong cohesive interaction forces act among the molecules and atoms after the dispersion of CdS:Ho nanoparticles in the ethylene glycol ${ }^{7}$. The Wada's constant changes with temperature are shown in Table 3.

The constant decreses with rise of temperature and particle size, which shows that solute solvent molecules are coming close to each other and the space between them, is decreasing with rise in temperature. This supports to the strong solute-solvent interaction in liquid solution ${ }^{10}$. The Wada's constant increases with Ho impurity doping as depicted in Table 2. It is a measure of change in internal energy of liquid solution as it undergoes a very small isothermal change. It is a measure of cohesive or binding forces between the solute and solvent interaction ${ }^{10}$.

Table 4.Variation of Rao's constant, acoustic impedance, free length with particle size and temperature of CdS:Ho nanofluid

\begin{tabular}{|c|c|c|c|c|c|}
\hline Temp $\left({ }^{\circ} \mathrm{C}\right)$ & $\begin{array}{c}\text { Particle } \\
\text { size }(n m)\end{array}$ & $\begin{array}{c}\text { Rao's constant } \\
\mathrm{R}=(M / \rho) V^{1 / 3} \\
\times\left(10^{-4}\right) \\
\left(\mathrm{m}^{3} / \mathrm{mole}\right)(\mathrm{m} / \mathrm{s})^{1 / 3}\end{array}$ & $\begin{array}{c}\text { Acoustic } \\
\text { impedance } \\
\mathrm{Z}=\mathrm{V} \times \rho \\
10^{4}\left(\mathrm{~kg} / \mathrm{m}^{2} / \mathrm{sec}\right)\end{array}$ & $\begin{array}{c}\text { Free } \\
\text { length } \\
\mathrm{L}_{\mathrm{f}}=K \\
(\beta)^{1 / 2}(\AA)\end{array}$ & $\begin{array}{l}\text { Velocity } \\
\mathrm{V}(\mathrm{m} / \mathrm{s})\end{array}$ \\
\hline 80 & 13.39 & 2.165 & 180.41 & 0.792 & 374.3 \\
\hline 100 & 16.73 & 2.175 & 182.91 & 0.781 & 379.5 \\
\hline
\end{tabular}

The variation of Rao's constant with temperature is as shown in Table 4. The Rao's constant increases with temperature and particle size. The molecules of liquid are not closely packed and as such there is always some free space between them ${ }^{11}$.

The variation of acoustic impedance with temperature and particle size are depicted in the Table 4. Acoustic specific impedance $Z$ increases with increase in temperature and particle size which indicates that there is strong interaction between solute and solvent ${ }^{12}$.

Intermolecular free length $\mathrm{L}_{\mathrm{f}}$ decreases with increasing particle size, Table 4 shows that there is enhanced molecular association which is confirmed by values of viscosity which increases with concentration ${ }^{10}$. Relative Association $R_{a}$ of the samples (Table 2) increases on doping the sample with Ho. Relative association is the measure of extent of association of the component in the mixture. The value of relative association increases with doping indicating strong interionic interaction ${ }^{12}$.

\section{Conclusion}

CdS nanoparticles have been synthesized by aqueous medium through chemical coprecipitation technique. The XRD results is indicated that the particle size of nano CdS doped with holmium is much small as compared to that of pure $\mathrm{CdS}$ and decreases with holmium loading. From XRD results it is clear that as temperature increases, particle size also increases. The change in particle size causes large variation in the physical properties since $1 \mathrm{~nm}$ size change may introduce a considerable change in the number of surface atoms with lower coordination and broken exchange bonds. Ultrasonic velocity through doped and undoped sample is measured and compressibility is computed. The compressibility is found to be increased. Also variation of compressibility of CdS;Ho nanofluid with various grain size have been carried out and found that compressibility increases with decrease of particle size. To study the elastic properties of the nano fluid certain important physical parameters such as adiabatic compressibility, specific acoustic impedance, relative association, intermolecular free length, Rao's constant, Wada's constant etc. are evaluated using ultrasonic velocity, density. The variations in these acoustic parameters with grain size and temperature are reported. 


\section{Acknowledgement}

The authors thank to Mar Philoxenos foundation and M.G. University, Kottayam for financial and technical support.

\section{References}

1. Antolini F, Pentamali M, Di Luccio T, Terzi R, Schioppa M, Re M, Mirenghi L and Tapfer L, Mater Lett., 2005, 59(24-26), 3181-3187; DOI:10.1016/j.matlet.2005.05.047

2. Klimov V I, J Phys Chem B, 2006, 110(34), 16827-16845; DOI:10.1021/jp0615959

3. Fukoka A, Sakamoto Y, Guan S, Shinji Inagaki, Noriaki Sugimoto, Yoshiaki Fukushima, Kaori Hirahara, Sumio Iijima and Ichikawa M, J Am Chem Soc., 2001, 123(14), 3373-3374; DOI:10.1021/ja004067y

4. Henglein A, Chem Rev., 1989, 89(8), 1861-1873; DOI:10.1021/cr00098a010

5. Petit C and Pilleni M P, J Phys Chem., 1988, 92, 2282.

6. $\quad$ Singh V and Chauhan P, Chalcogenide Letters, 2009, 6(8), 421-426.

7. Rajulu A V and Mabu P S, Bull Mat Sci., 1995, 18(3), 247-253; DOI:10.1007/BF02749662

8. Langford J I and Wilson A J C, J Appl Cryst., 1978, 11, 102-113.

9. Mukherji S, Kumar S and Das D, Nanosci Nanotech Lett., 2012, 4(1), 110-116; DOI:10.1166/nnl.2012.1275

10 Paladhi R and Singh R P, Acustica, 1990, 72, 90-95.

11. Nikam P S and Mehadi Hassan, Asian J Chem., 1993, 5(2), 319-321.

12. Anwar Ali and Anil Kumar Nain, Acoustics Letters, 1996, 19(9), 181-187. 